\title{
A review of European research on consumer response to nutrition information on food labels
}

\author{
Klaus G. Grunert • Josephine M. Wills
}

Received: 14 December 2006 / Accepted: 27 February 2007 / Published online: 14 April 2007

(C) Springer-Verlag 2007

\begin{abstract}
The aim of this study was to review research conducted in 2003-2006 in the EU-15 countries on how consumers perceive, understand, like and use nutrition information on food labels. Based on a search of databases on academic publications, Google-based search, and enquiries directed to a range of food retailers, food companies, consumer associations and government agencies, a total of 58 studies were identified. These studies were summarised using a standard format guided by a model of consumer information processing, and these summaries were subsequently processed using the MAXqda software in order to identify key findings and common themes across the studies. The studies show widespread consumer interest in nutrition information on food packages, though this interest varies across situations and products. Consumers like the idea of simplified front of pack information but differ in their liking for the various formats. Differences can be related to conflicting preferences for ease of use, being fully informed and not being pressurised into behaving in a particular way. Most consumers understand the most common signposting formats in the sense that they themselves believe that they understand them and they can replay key information presented to them in an experimental situation. There is, however, virtually no insight into how labelling information is, or will be, used in a real-world shopping situation, and how it will affect consumers' dietary patterns. Results are
\end{abstract}

\footnotetext{
K. G. Grunert $(\triangle)$

MAPP-Centre for Research on Customer Relations

in the Food Sector, University of Aarhus,

Haslegaardsvej 10,

8210 Aarhus V, Denmark

e-mail: klg@asb.dk

J. M. Wills

EUFIC-European Food Information Council,

Rue Guimard 19,

1040 Brussels, Belgium
}

largely in line with an earlier review by Cowburn and Stockley (Public Health Nutr 8:21-28, 2005), covering research up to 2002, but provide new insights into consumer liking and understanding of simplified front of pack signposting formats. There is an urgent need for more research studying consumer use of nutritional information on food labels in a real-world setting.

Keywords Nutrition information · Food labels . Consumer research $\cdot$ Signposting

\section{Background}

Getting consumers to eat more healthily is no trivial task. While health is valued by everybody and therefore is one of the fundamental drivers of human behaviour, attempts to change eating patterns by informing consumers about the link between diet and health have been difficult. One of the major instruments in trying to bring about more healthy eating patterns has been nutrition labelling. Nutrition labelling is an attempt to provide consumers, at the point of purchase, with information about the nutrition content of individual food products, in order to enable consumers to choose nutritionally appropriate food. It is an attractive instrument for a variety of reasons: it supports the goal of healthy eating while retaining consumer freedom of choice, and it reduces information search costs for consumers, which should make it more likely that the information provided is actually being used.

However, there have been indications that nutrition labels may not be used, even though consumers say that they do, and that they may be misunderstood. These are questions that can be investigated by conducting consumer research. A few years ago, the European Heart Network (EHN) sponsored a systematic review of the studies that 
had been conducted up to 2002 (Cowburn and Stockley 2005; European Heart Network 2003). They found that the majority of the 103 papers identified in this search came from the USA and the UK. They also concluded that reported consumer use of nutrition labels is high, although actual use appears to be considerably lower. Consumers seem to be able to understand certain key terms and also apply the information in simple tasks, but confusion increases with complexity of the information and the task to which it should be applied. They pointed out that interpretational aids may serve a very useful function in getting consumers to use this information more and in a better way.

Since 2002, there has been considerably more discussion on nutrition labels, and a good deal has actually concentrated on interpretational aids. One central idea has been the distinction between labelling the front and back of packages, where the more common complex nutrition table on the back of the product could be supplemented by a simplified label on the front that summarises key information. In the process in which key stakeholders in the European food sector tried to clarify their own position with regard to such proposals, more research has been commissioned. A small part of this has been published in academic journals, but the bulk of it is "grey" literature that has been made available in the form of reports available on request or downloadable from websites.

The aim of the present paper is to review research that has become available after the 2002 deadline used by the Cowburn and Stockley review (European Heart Network 2003; Cowburn and Stockley 2005). In addition, the present review is limited to research done with European consumers, more specifically research done in the EU-15 countries.

\section{Methodology}

There have been separate search methodologies for studies published in academic journals and other studies, especially stakeholder studies. For publications in academic journals, the following databases were searched: Amed, Assia via CSA, Biological Science, Biosis Biological Abstracts, Blackwell Synergy, CAB Abstracts, CAB Health, Cinahl, Cochrane, Ebsco, Embase, Emerald, Eric, Jneb, Medline, Oxford Journals, PyscINFO, Science Citation Index, Science Direct, Scopus, Social Sciences Index, Sociological Abstracts, Springer Link and Wiley Interscience. In all databases, a hierarchical search procedure was implemented: (1) food or nutrition or diet, (2) labelling or labelling or label or information or point-of-choice or pointof-purchase or packet or package or food or industry or "food industry" or nutrition or policy or "nutrition policy" and (3) consumer. This procedure led to about 3,000 hits (including multiple counts due to the same source being in several databases). For all of these, abstracts were perused to determine the relevance of the paper. This resulted in 53 papers of potential relevance, for which the full text version was obtained. Papers mainly dealing with non-nutrition aspects of labelling, such as quality labelling and labelling with regard to production/processing methods [e.g. use of genetically modified organisms (GMOs), irradiation and organic production], were screened away. Papers dealing with labelling information for allergenic consumers were likewise screened away. The lists of references of the papers retained were then perused for potential additional relevant sources, but none were found. This resulted in 13 peer-reviewed papers.

In order to locate studies not published in academic journals, the second author contacted food companies, retailers, modern restaurants, consumer associations and government agencies, directly and indirectly, via the EU Platform for Action on Diet, Physical Activity and Health, and asked for relevant material based on a short brief. In addition, websites of organisations known to have been involved in the debate on nutrition labels were investigated. Finally, a Google search was conducted. While we cannot ascertain with absolute certainty that we have located all relevant studies, we can note that an informal circulation of the results among European stakeholders has not resulted in any feedback pointing out missing studies.

These procedures resulted in the identification of 45 reports or PowerPoint presentations. Thus, the whole procedure resulted in the identification of 58 relevant items, listed in the Appendix. Information extracted from the items was guided by a theoretical framework, developed in the next section.

\section{Theoretical framework}

Before going through the studies found, it is useful to consider which types of effects are possible and of interest. For this purpose, we developed a simple theoretical framework, shown in Fig. 1. It is inspired by two streams of research of importance for analysing effects of nutrition information on consumers, namely consumer decisionmaking and attitude formation and change. Research on consumer decision-making (Peter et al. 1999; Solomon et al. 2006; Bettman 1979; Bettman et al. 1998) deals with the processes determining product choice in a situation where multiple options are available, and how choice is affected by information on the choice alternatives. Research on attitude formation and change deals with how consumers process information to which they are exposed, make meaning of it and evaluate whether the information has any positive or negative significance to them, which is 
Fig. 1 Theoretical framework

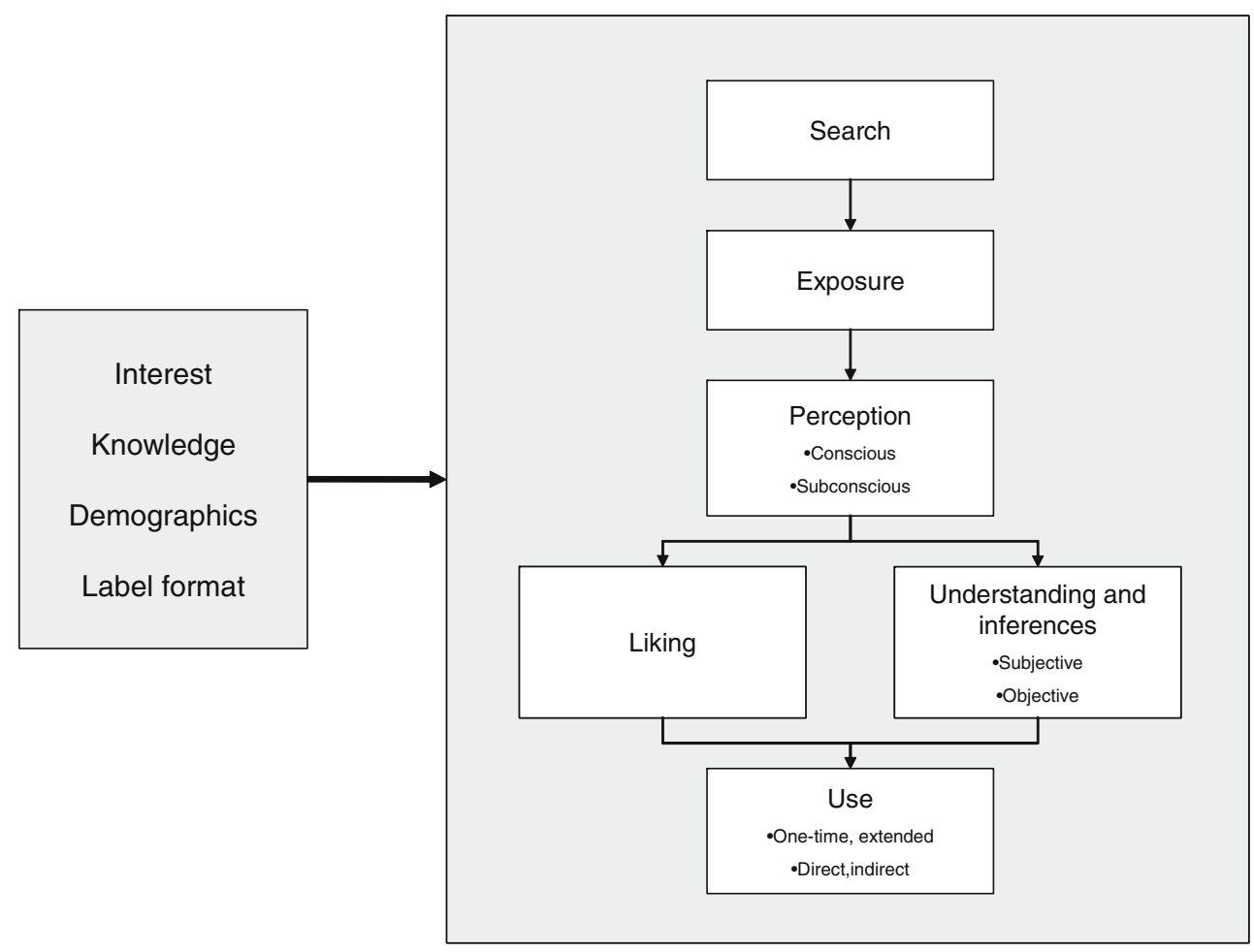

usually regarded as a prerequisite for the information to have any effect on their behaviour (Eagly and Chaiken 1993; McGuire 1985; Petty and Cacioppo 1981).

The model in Fig. 1 has been developed based on these two streams of research. Its basic structure is inspired by classic step models of consumer decision-making (e.g. Engel et al. 1968) and hierarchy of effects models of communication effects (e.g. Lavidge and Steiner 1961). Only labels to which consumers are exposed can be expected to have any effects. The likelihood of exposure is increased if consumers actually search for the label information, though active search is not a necessary precondition for exposure, which may be accidental. Exposure leads to effects on subsequent behaviour only when the information is perceived. Perception can be conscious or subconscious, though conscious perception is expected to have stronger effects on subsequent behaviour. Perception leads to understanding, which is the meaning the consumer attaches to what is perceived.

In analysing understanding, it is important to distinguish between subjective and objective understanding. Subjective understanding is the meaning the consumer attaches to the perceived label information and covers also the extent to which consumers believe they have "understood" what is being communicated. Objective understanding is whether the meaning the consumer has attached to the label information is compatible with the meaning that the sender of the label information intended to communicate. These may be quite different. Understanding is to a large degree a question of inferences (Kardes et al. 2004). Consumers relate the perceived information to their pre-existing knowledge and use this to infer meaning.

Another effect of perception and processing of the information may be liking of the label. Consumers may like the label-for example because they find it easy to understand and useful, or also because they like the symbols and colours used. Liking need not be linked to understanding, but can have impact on use of the label, as a label that is liked can lead to a more positive evaluation of the product even when it is not understood (so-called peripheral information processing, see Petty and Cacioppo 1986).

Finally, the label information may be used in making choices. Here we can distinguish between direct and indirect effects, and between one-time and extended effects. Direct, one-time effects are the effects of the label information on the choice of the product that bears the label and in the context of the purchase where the label information was perceived. Direct, extended effects are effects on the purchase of the product bearing the label over time, where information effects may be cumulative and may extend after the product may have ceased bearing the label or after the label information has been altered. Indirect effects are effects on all other food purchases. The processing of label information may alter the overall pattern of food purchaseslabel information may result in the consumer learning about which product categories are more healthy and which are less, and this may alter the overall pattern of purchases such that categories now regarded as less healthy are bought less and categories regarded as more healthy are bought more often. 
Search, perception, understanding and use will be influenced by a number of factors. In Fig. 1 we mention the most prominent ones that have been discussed in the literature and/or are likely to play a role based on general consumer behaviour theory. Interest in nutrition issues can be expected to have effects on all phases of the process. Knowledge about nutrition issues can be expected to have effects especially on understanding and use. Consumer demographics are often discussed as determinants, though they are more likely to be correlates of actual determinants, such as interest in and knowledge about nutrition, price consciousness or health status. On the information supply side, the format of the label obviously is expected to have a major impact. This framework was used to extract information from and evaluate the studies found.

\section{Information extraction procedure}

All studies were summarised in a standard format, structured by the nature of data collection (qualitative/quantitative), the sample, the study design, the theoretical approach used, which parts of the model in Fig. 1 were covered and main results. All information was entered into MAXqda, a software for qualitative data analysis. The software was used for information retrieval in the process of deriving main results across the 58 items. Key characteristics of the 58 studies are summarised in the Appendix.

It should be noted that academic publications and material from stakeholder-initiated research are usually not reported to the same standards. Stakeholder-initiated research has been in almost all cases conducted by market research companies, and both the research itself and the way it is reported follows industry standards for the market research business. This means a strong emphasis on sampling, recruitment of respondents and, in the case of qualitative research, characterization of individual informants by key characteristics. It also means an emphasis on simple and descriptive statistics and, in the case of qualitative research, no information on modes of analysis of the data. Academic publications have gone through the quality control of refereed publications, and information on samples, measurements and statistical methods are usually complete. In dealing with these differences in standards of documentation in this review, two measures have been taken.

First, we list in Table 1 major quality criteria used in assessing the studies and the results of the assessment. A few things are worth noticing. The vast majority of the studies - also many of those published in academic journals do not specify any theoretical framework or background. This is somewhat astonishing, since we are dealing here with a complex aspect of human behaviour, and lots of relevant theoretical insights are available in areas like consumer psychology, cognitive psychology, sociology and economics (Baltas 2001). Also, as noted above, stakeholder-initiated research is many times deficient in describing the tools of analysis used, mostly when doing qualitative research. Finally, for a number of studies details of sampling and data collection are unclear. This last group of studies has received the least weight in the review, and in the few cases where these are nevertheless cited we will mention their limitations. We have decided not to discard them completely from this review, as they can provide important hints for future research-for example, the only sources giving some evidence on real sales impact are in this category.

Second, we have looked for convergence across the 58 items. Results that seem to be consistent across several studies employing different methodologies and samples receive more weight in this report. This is consistent with the principles of triangulation and convergent validity commonly applied in the social sciences (e.g. Bryman and Bell 2003).

Table 1 Quality assessment of studies

Major quality criteria used in assessing the studies

1. For all studies

(a) Theoretical framework specified

(b) Selection of respondents/subjects/ informants well-reasoned and clearly described

(c) Choice of methodology for data collection appropriate and clearly described

(d) Choice of tools for data analysis appropriate and clearly described

(e) Results clearly reported

2. For cross-sectional surveys

(a) Sample representative of population

3. For experimental studies

(a) Adequate assignment of subjects to experimental groups

(b) Adequate methodology in within-subjects designs
\# studies found wanting on criterion (overall $n=58$ )

49 (all except $4,14,26,33,43,49,53,55,56$ )

$9(1,27,30,31,40,42,45,46,52)$

$14(3,8,9,15,31,35,36,40,41,42,45,46,51,52)$

$22(3,8,9,13,15,17,20,21,23,25,28,31,35,36,37$, $40,41,42,45,51,52,58)$

0

$5(34,37,40,42,46)$

0

0 


\section{Main results}

In the following, numbers in parentheses refer to the studies listed in the Appendix

First, we can note that an impressive amount of work has been done with consumers on nutrition labels within this relatively short time period. We believe that two events have been instrumental in this. One is the move from the European Commission to re-look at the 16-year old Directive on Nutrition Labelling (90/496/EEC). The other is the debate on simplified front of pack labels ("signposting"), fuelled by some consumer associations, some major retailers and notably the work done by the UK Food Standards Agency.

There is a clear difference between the studies done in academia and published in refereed journals and the studies commissioned by stakeholders and usually carried out by a market research company. The former are typically based on smaller samples, often with limited geographical reach and partly driven by considerations of cost and convenience. On the other hand, they use advanced statistical methods and aim at explaining consumer behaviour, often with a combination of demographic, attitudinal and economic factors. The latter are typically based on samples of considerable size - series of focus groups with geographical spread when doing qualitative work, large quota samples when doing quantitative work. The methods used, on the other hand, are simple. Analysis of quantitative data is usually restricted to descriptive statistics, and there are only very basic attempts at explaining the behaviour described.

There are three main types of studies: cross-sectional surveys, qualitative studies mostly employing focus groups and experiments. Even within these categories, research design and methodologies employed vary considerably, so that many results are not readily comparable.

\section{Interest}

Across the studies covered by this review, there is a surprising degree of consistency in the conclusions about consumer interest in nutrition information and in their interest in getting this information from nutrition labels on food products. Participants were generally aware of the overall link between food and health, indicate an interest in nutrition and are also interested in getting information about the nutritional properties of the food they eat $(2,3,6,9,11$, $12,20,33,38,41,46)$. Nutrition information is not, though, the top interest with regard to food, even in those countries where nutrition issues are of higher interest. In a Dutch study, for example, informants would rather talk about tasty food, food safety or issues like GMO before getting into nutrition (55). In a Swedish study respondents ranked health and nutrition sixth in importance after food safety, freshness, taste, free of pesticides and animal welfare (50). In a study on what kind of information consumers would like to see on meat labels in Europe, nutrition information was rated as of medium importance, lower than information on origin and best before date (5); in an Irish study the top five items respondents wanted from labels were best before data, additive content, fat content, production date and origin (19).

There are numerous qualifications. They refer to types of consumers, types of products, type of situation and type of label. Across the studies, a recurrent theme is that certain demographic groups have a higher interest in nutrition information. Women were generally more interested than men, and parents of children living at home, especially preteenage children, were more interested than pre-kids adults or empty nesters $(6,20,24,37,58)$. However, young women may be interested in nutrition for reasons of weight control $(21,35)$ and aesthetic concerns $(58)$. There was also an age effect with older informants more interested due to a generally increased health concern $(20,24,33,58)$, though this baseline interest may be counteracted by more difficulties in processing information in the high age groups. There seems to be a geographical/cultural effect as well, roughly following a North-South distinction, which can be seen best in the study by the European Commission (13). Informants in the Nordic countries, in the Netherlands and in the UK were most interested, whereas informants in countries like France, Greece and Spain were not so enthusiastic about the prospects of receiving more nutrition information. The UK may be special due to the high media attention that has been given to nutrition, as well as a history of more widespread application of nutrition information on labels.

However, some consumer differences cannot be attributed to demographics or country alone. In some of the studies, informants clearly also differed in their general attitude to food and health. There may be a trade-off between health and nutrition on one side and price and/or taste on the other, and some take sides for taste and/or price and attach lower importance to health and nutrition (e.g. 14, 27); there may be also a notion of resistance against attempts to impose a "scientific" approach to something that is very much linked to enjoyment (e.g. 15, 27).

Consumers are more interested in nutrition information for some products than others. In several studies, informants expressed a view that nutrition information is less relevant for fresh products like fruits, vegetables and meat $(13,38)$ and informants expressed reservations with regard to products that are regarded as a treat $(13,24,27)$, which was especially clear in those studies dealing specifically with chocolate $(35,36)$. Products where interest is highest were typically processed products with a low degree of transparency, like ready meals $(13,24,38)$.

When consumers are interested in nutrition information, this does not imply that they want to get this information 
from labels. They are generally positive about labelling, especially if it is applied systematically to all packaged products (e.g. 12, 13). When compared to other sources with high credibility like doctors, dieticians, and also friends and relatives, a Dutch study found that interest in getting information from them is generally higher (55).

Expressed interest was often linked to situations where a product is bought for the first time, and where information need is highest $(1,16,20,27,38)$. Several informants across studies also mentioned that they are not interested in nutrition information in situations where they are time pressured $(13,20,27,28,34,36)$, which goes for many shopping situations.

The nutrition information spontaneously mentioned first as of interest by informants in the qualitative studies is often calories and/or fat $(13,23,35,58)$; others are sugar, salt, carbohydrates, vitamins and calcium. Informants also mention additives, "artificials" (colours, preservatives, flavours, see 35), E-numbers and sweeteners. Results of the quantitative studies differ in details, but usually have fat and/or calories, salt and sugar at the top of the list $(1,6,19$, $22,24,32,34,40,46,57)$.

\section{Knowledge}

While nutrition knowledge was not the primary aim of investigation in the studies reviewed, many address it as background information and possible determinant of label understanding and use. There is quite good consistency across the qualitative studies in the way nutrition knowledge is expressed. Informants express uneasiness and confusion, and are frustrated by what they perceive as contradictions among experts and the fact that new and different information is emerging all the time. There is generally a good understanding of calories (e.g. 15, 35, 37, 44), but confusion about nutrients.

The quantitative results are largely in line with this. Respondents could often express agreement that one should eat less food with sugar and fat and more fruits and vegetables (e.g. 22), a finding corroborated in other studies, both quantitative and qualitative. In the BEUC (6) study in five European countries, when presented with a product high in carbohydrate/sugar content, $12 \%$ of respondents thought it was nutritionally very good and $54 \%$ believed it was rather good. For five questions testing nutrition knowledge, correct answers varied from 19 to $51 \%$. In an Irish study, more than half of the respondents answered "don't know" when asked how much salt or fat they should eat on a typical day (44).

\section{Search}

In our conceptual model, search referred to effortful activities by consumers to get access to information on nutrition labels, in contrast to situations where consumers are accidentally exposed to these labels and then may or may not process the information on them. On theoretical grounds, this distinction is important, because when consumers engage in effortful search, then the subsequent processing of the information will be more in-depth and chances of the information actually affecting food choices are higher. The distinction between effortful search and accidental exposure is almost never made in the studies analysed. The way in which the extent of effortful search can be investigated is either by consumers reporting on their own behaviour, or by observations in a real-world environment. The only observational study in this review is the one by Waitrose (58), where informants tended to make only limited effort to see labels. There were many studies dealing with selfreported behaviour, but usually they did not distinguish between effortful search and accidental exposure. There were two exceptions. The qualitative study by European Food Information Council (15), based on focus groups in France, Germany, the Netherlands and the UK, led to the impression that (some) consumers seek out labels actively in the UK, but less so in the other countries, which may be related to the differences in availability of and familiarity with labels that exist between these countries. In the quantitative French study by Consommation Logement et Cadre de Vie (11), based on a quota sample of $850,22 \%$ reported that they are interested in nutrition labels and search for them actively, whereas another $41 \%$ reported that they read the information when they are exposed to it accidentally rather than seeking it out.

\section{Perception}

Since our conceptual model is post hoc, categorisation of research results is not always straightforward, and there is a fine borderline between perception, understanding and use. Perception, as defined above, deals with whether the label information actually is taken up by the consumer. Most of the research results categorised under perception have to do with the question whether consumers read the labels. Research on inferences made during or after reading the information will be dealt with under understanding.

In our conceptual model, we have made a distinction between conscious and subconscious perception. Exposure is known to lead to subconscious activation of certain familiar concepts the recipient of the information is exposed to. None of the studies perused addressed this.

Ways in which reading and awareness are measured differ considerably between studies, and results are thus not readily comparable. In the ACNielsen (1) study, which was conducted in 38 countries, $18 \%$ of the European respondents claimed that they "always" check the nutrition information on the package, with highest rates reported 
for Portugal (44\%), Italy (31\%) and Denmark (30\%). In other studies, the percentages reporting to check nutrition information always or occasionally are correspondingly high, e.g. 52\% for a study for Kellogg's in the UK (30), $65 \%$ in an Irish study (44), 50\% in a Swedish study (50) and (roughly comparable) $63 \%$ in France (11). In other studies the figures are still higher $(31,40)$, though the samples used there are either not clearly reported or of questionable representativity. Generally, such figures should be interpreted with caution and probably contain a good deal of over-reporting, and it may also not always be clear to respondents what the term "nutrition information" means. Some consumers are known to confuse nutrition information with ingredients lists, and also with nutrition claims, which are designed to attract attention to a much higher degree than nutrition tables [e.g. in the BEUC study (6), 59\% claim that nutrition claims catch their attention and that they read them].

It is therefore more interesting to look at how the figures differ by consumer groups and situations. In line with the differences between demographic segments noticed in the section on interest, women report more reading of nutrition labels than men $(19,30,49)$, and also some of the other factors mentioned in the section on interest (older consumers, parents) occur again. As for situation, several studies address whether a product is being bought for the first time, which increases reported reading rates $[41 \%$ for the European part of the ACNielsen study (1), see also (27, $28)$, and in the qualitative studies there are indications that time pressure decreases likelihood of reading nutrition information (27). Also selective reading of information on certain nutrients is reported, mainly following the results reported above for interest. In two large comparative studies, information on fat content and calories (in that order) were reported most often as being read $(1,6)$.

Self-reported reading measures are based on respondents' interpretation of their own past behaviour and may be of limited predictive power for perception of future labelling initiatives. Perception of new information can be analysed in field experiments or by tachistoscopic tests in the laboratory. Steenhuis et al. (47) introduced new labelling in an experimental set-up of Dutch supermarkets, supported by an educational campaign, and found that while $50 \%$ of respondents had noticed the intervention, only $25 \%$ had noticed the labels. A tachistoscopic investigation for Kellogg's (29), involving 1-s and 2-s flashes of packages with an added GDA label, showed perception rates of $3-4 \%$ for the 1 -s flash and about $20 \%$ for the 2 -s flash.

\section{Liking}

A good deal of research has been done on liking - whether consumers like the idea of simplified labels and front of pack signposting in general, but in particular how they like different types of label formats. This covers both qualitative studies, where informants are confronted with different types of label formats and are openly asked for their reactions, and for quantitative research, where different formats have to be rated according to general preference or according to a number of different dimensions.

At the general level across the studies, consumers generally like the idea of improved nutrition labels, and they like the idea of front of pack signposting as a shopping aid (e.g. 21, 26). Having said that, opinions begin to differ considerably once people are confronted with concrete proposals for, or examples of, simplified nutrition labels. In order to reconcile the various findings, we would like to hypothesise, based on the findings analysed, that there are three basic considerations that guide consumer liking for various signposting formats. First, consumers like simplification (e.g. 8, 16, 20, 27). They know that in a real shopping situation they have limited time and possibility to look at back of pack labels, of which they are critical because of bad legibility and unknown terms (see below section on understanding). They also find it difficult to interpret various nutrients, compare numbers, and are generally wary about the cognitive load that comes with trying to make use of nutrient tables. Second, however, when presented with simplified information like traffic lights or health logos, consumers still would like to know what this simplified information stands for and how the red light or the health logo has been arrived at, and are wary of the fact that somebody may have made a decision for them that they do not understand, even when this someone has good credibility (e.g. 3, 16, 27, 37). Third, nutrition information can create resistance in consumers when they feel coerced or pushed to make choices that they do not want (e.g. 8, 12, 17, 20, 25, 35, 37).

Obviously, these three considerations have different and partly incompatible implications, and nutrition labelling systems that consumers like therefore have to be a compromise balancing these different criteria. Also, consumers will differ in the weight that these different criteria have for them. We believe that this idea of a trade-off in the mind of the consumer can help in providing structure to a range of the findings on liking of various formats.

The research done on liking of various formats can be divided into four groups or issues

The first deals with comparing the three major groups of formats that have been discussed: traffic light systems, GDA-based systems and health logos/ratings. Simple traffic lights and health logos were mostly less liked (e.g. 10, 12, $37,53)$. They are formats that provide the most simplification, but fail on the other two criteria. Simple traffic 
lights have been characterised as "too didactic" (21) or "paternalistic" (37), and similar reactions have been observed for health $\log 0$ s (27), although reactions there depend on the perceived intent. A "be treatwise" or an "an occasional treat" logo, tested for use on chocolate bars and perceived as a mild reminder not to overindulge, was received positively $(27,36)$. Energy labels, which are another way of presenting information with a high degree of simplification, were generally liked (16), but there were also concerns that the purpose of energy labels is to encourage people to count calories, which has a coercive element (17).

When comparing multiple traffic lights and GDA-based systems, the results are not clear-cut (e.g. 7, 10, 12, 37, 51). Also, there is a hybrid format, the colour-coded GDA format, which combines elements of both. Referring back to the three criteria for liking discussed above, multiple traffic lights seem to outperform GDA-based systems in simplicity, but the GDA-based systems score higher on the two other dimensions. In a study commissioned by Tesco (51), for example, Tesco's GDA system won higher agreement on the statement "gives me all the information I need" compared to the traffic light system. The colourcoded GDA clearly outperformed the multiple traffic light in terms of liking in a Food Standards Agency study (24), with $65 \%$ preferring the colour-coded GDA as compared to $30 \%$ for multiple traffic lights. This result is compatible with our reasoning about liking being based on three dimensions: the colour coding provides the simplicity (since the processing of the label can be limited to the colours, ignoring the rest), but the GDA information gives reassurance by providing numbers that one, in principle, could go back to for verification, giving an impression of more transparency and less paternalism.

The second group comprises studies comparing colourcoded systems with other systems. Results here show that the use of colours to provide information seems to be liked by many consumers $(3,28,35)$. In the Food Standards Agency studies, multiple traffic lights and the colour-coded GDA emerged as the two formats clearly liked most, as noted above, and when comparing the colour-coded GDA with a monochrome GDA, respondents overwhelmingly preferred the coloured one $(23,25)$. Variations of this general theme, like Sainsbury's Wheel of Health (that combines colour coding with giving numerical information on nutrients) also seem to obtain high degrees of liking.

A number of studies have compared different formats of providing GDA-related nutrition information. One question addressed is whether GDA charts should contain information in grams, in percentages or both. Results were mixed (10, 25, $28,35)$, with informants in the qualitative studies expressing both liking and disliking percentages. Reasons given for liking in the qualitative studies are that they simplify the information and make it more difficult to ignore (28), reasons for disliking that they increase the complexity and do not add extra information $(25,28)$ and that some report having had problems with them already back in their school days (25). In a quantitative study comparing three formats in three countries, a format containing grams per serving and percentages was more liked than formats containing $\%$ only or grams and a bar chart in the UK and Germany, with no clear preferences in France (10). Various forms of visualisation, like bar charts, pie charts and different uses of colour have been tried $(23,29,36)$, but have mostly been found to be disliked as being too complicated.

Several studies have looked at liking of reporting nutrition information per $100 \mathrm{~g}$ or per serving. Participants in the studies generally agreed that it is important that it is absolutely clear what a "serving" is, and often this is far from the case, but apart from that preferences for these various formats seem to vary a good deal, with preferences found both for information per $100 \mathrm{~g}$ (38), for information per serving (3, $10)$ and for providing both $(34,40)$. One study indicates that these preferences vary by product (18), and another indicated that preferences for one or the other may also depend on what the information is to be used for-comparison between products or how much of a nutrient is present in a serving of the product (16).

\section{Understanding}

Research on perceived understanding of existing nutrition labels is somewhat equivocal. On the one hand, when asked in quantitative surveys whether they understand such labels wholly or partly, the majority of respondents usually answer yes $(1,6,11,19,22,31,44,57)$. At the same time, respondents usually also answer yes to questions on whether such labels need improvements $(6,11,31,34)$. In qualitative studies, the critical aspects predominate. Existing nutrition information on food packs is criticised for being hard to find, having poor legibility, using unknown terms and being confusing $(9,15,16,21,23,27,58)$. In the extensive qualitative study on labelling by the European Commission (13), criticism related to finding information difficult to locate, difficult to read, concealed by stick-on labels, small font size, multi-lingual labels, lack of colour contrast letters/ background, lack of standardisation and "obscure" wording.

The overarching result with regard to the various new front of pack signposting schemes proposed is that participants in the studies generally find them easy to understand. In quantitative studies comparing various formats (typically traffic light systems, GDA-based systems and health logos or rating systems), levels of self-rated understanding did not vary very much $(12,51,53,57)$. In the qualitative studies conducted on behalf of the Food Standards Agency $(21,23)$ in the UK, traffic light formats 
and colour-coded GDA formats were viewed as best in terms of understanding, whereas reactions were a bit more mixed with regard to some of the other formats. Thus, comments on both simple traffic lights and health symbols included that it was difficult to know what they cover, and a monochrome GDA was regarded as more difficult to understand than a colour-coded one. Other qualitative studies focusing specifically on the two most debated systems, multiple traffic lights and various versions of GDA-based systems, also found generally that participants viewed them as easy to understand $(8,23,36,45)$. For traffic light formats, the picture may change a bit though, when consumers are confronted with them not in a single product context, but in a meal context; understanding what the system means when trying to compose a meal may be different than understanding what it means when choosing a particular product (36). The different variations of calorie signposts tested by the European Food Information Council (16) were also perceived as easy to understand.

There have been a few studies on how consumers infer perceived overall healthiness of a product from the information provided. One interesting result from a multi-country study (France, Germany, UK) was that respondents rated the overall healthiness of a product as higher when the product was displaying a health logo or health rating system, as compared to formats providing a range of indicators, such as multiple traffic lights and GDA systems (10); a similar result was obtained in a Dutch study (18). A qualitative study (28) suggested that consumers may combine information from the nutrition label with information from the ingredients list to arrive at inferences about overall healthiness. Generally, we know little about the inferences made when processing nutrition information on packages.

Objective tests of understanding come in various forms: asking people to replay part of the label information, asking them to evaluate a given product based on a given nutrient, asking them to compare two products based on a given nutrient, asking them to evaluate the overall healthiness of a product. Usually, a majority of respondents can correctly replay information given on one nutrient, though the percentage of correct answers may depend on the format in which the information is given. For example, in a study conducted by Cereal Partners Worldwide (10), when asked to indicate the correct amount of whole grain contained in a cereal product, 91\% could answer correctly after having seen a product with a GDA format referred to as "industry standard" (grams and percentages for five key nutrients including calories), compared to $71 \%$ when the same information is given in a bar chart format. On the other hand, when asking for which of the nutrients on the label contained the highest proportion of the GDA, 60\% could give a correct answer when using a bar chart, compared to $37 \%$ for a pie chart (29). Different formats may thus facilitate processing in different ways for different tasks. This is, of course, not surprising. In one of the Food Standards Agency studies (24), respondents had to evaluate whether a product was high, medium or low on two key nutrients. Of four formats tested, the multiple traffic light led to most correct answers, ahead of the colour-coded GDA information, a finding that may be related to the fact that the multiple traffic light provided exactly this information, and nothing else. When, however, respondents were asked which of two products was higher on these two key nutrients, the colour-coded GDA outperformed the traffic light system. Both clearly outperformed a simple traffic light system. In a study commissioned by Which? (57), the multiple traffic light system clearly outperformed various versions of a GDA-based system when the task was to find out whether the level of four nutrients in the product was low, medium or high. Most of these results can be interpreted on the background of the simple hypothesis that share of correct answers increases in line with a decrease in the requirements for processing of the information provided in order to give a correct answer. In the Which? study, the four formats tested did not differ in the likelihood of aiding respondents to classify a given product as healthy or unhealthy (according to criteria predefined by the Which? food team), with about half of the respondents classifying the product incorrectly (according to the Which? criteria). However, when confronted with pairs of products, $90 \%$ of the respondents could correctly identify the product that was healthier (again, according to a predefined objective criterion), with the multiple traffic light system leading to more correct classifications than the three GDA-based systems (97 compared to $87 \%$ ).

There were mixed results with regard to the effects of demographic factors on understanding. Concerning objective understanding, the Food Standards Agency (22) study and the French study by Consommation Logement et Cadre de Vie (12) found that the older age group and the lowest social status groups/less educated respondents performed worse than the rest on the indicators of objective understanding. The Which? study (57) found that respondents in lower socioeconomic groups had more difficulties in correctly classifying key nutrients as high, medium and low when confronted with the GDA-based system used by Tesco (colour-coded, but not traffic lights). But in terms of subjective understanding, research commissioned by Tesco (51) showed that ethnic minorities, respondents over 55 and respondents from the DE social grades generally found both GDA-based labels and multiple traffic lights easy to understand, and the experimental study by Unilever (53) could not find effects of education in perceived understanding.

There are limitations in the research that has been conducted on understanding of nutrition labels. As for subjective understanding, it is reassuring to know that consumers 
mostly feel they understand the information, but with regard to any desired health or nutrition effects of labels it would be more important to analyse what they think they have understood, i.e. to shed more light on the inferences made from the label. This topic has only been touched upon. As for the objective understanding tests, most of them do not go beyond demands for simple replaying some of the label information, and in addition they have all been conducted in forced exposure situations that are not typical for real-world shopping.

\section{Use}

Research on use of nutrition information on labels is in four categories. The first is self-reported use of labels already existing. The second is imagined (hypothetical) use of new label formats not yet on the market. The third covers studies on how label information affects intentions to buy the labelled products. Finally, there could in principle be studies on actual use, though only limited information was found in this category.

Measures on self-reported use are close to measures on self-reported perception, the difference being in questions posed, such as "do you usually read..." as compared to "do you usually use...". Since perception and use are conceptually different-you may read (and understand) labels, but not use them in your decision-making - we keep this distinction here, but when it comes to self-reporting measures, measures of reading and using are probably addressing much of the same thing. Not surprisingly, therefore, the results reported now on self-reported use follow closely the results described above on self-reported reading.

Both in qualitative and quantitative research, many participants claim that they use nutrition information from packages. For example, in the French study by Consommation Logement et Cadre de Vie (11), 33\% of respondents claimed they buy based on nutrition claims and $24 \%$ based on nutrition labels. Figures as high or higher have been reported also for France by Mannell et al. (34), for Greece by Drichoutis et al. (14), for the UK by the Food Standards Agency (22) and the Institute of Grocery Distribution (27), for Spain by Gracia et al. (26), and for Sweden by Svederberg et al. (50). A range of demographic effects have been reported, including higher self-reported label use by women, by older consumers, by more educated consumers and by consumers in the higher social strata, though the results do not compare easily across the various studies. Price interest correlates negatively with self-reported label use $(14,26)$. Label use is positively linked to buying new products $(1,16,27)$ and negatively to time pressure $(27,20)$. There are also differences according to product category, and the main tendency seems to be that self-reported use is higher for products with a higher degree of processing $(34,38,45)$.
When testing new formats, in some studies participants were encouraged to speculate about the ways in which they would use the information. This applies especially to health logos, traffic light systems and GDA-based systems. One finding is that informants in some qualitative studies underlined that red lights or other deterring signals, including unfavourable GDA data, would not prevent them from eating products they like for their taste or as a treat, even though this may lead to some moderation $(3,27)$. In some of the Food Standards Agency research, informants could imagine using this type of information as a heuristic in screening products, especially when the information is colour-coded, and especially in cases where there is a range of product alternatives (in the same product category) that may differ in their "colour range" (23). Some informants believed that colour-coded information would be more difficult to ignore than other formats and therefore would have more impact on their purchases (25), and some foresaw some confusion when signposting information was to be used to choose not only single products, but whole meals or weekly shopping baskets (21). In a Dutch study (17), informants imagined that health logos would mostly be used when choosing products where they were in doubt about the product's health status.

A few studies measured future buying intentions for products that were shown with and without nutrition signposts $(18,53)$. They found that the buying intentions for the less healthy products decreased when they had the logo or signpost. This effect was largely independent of the format used.

There were only a few references to anything resembling real-world use of nutrition labels. The Dutch experiment by Steenhuis et al. (47) experimentally introduced fat labels in some supermarkets and measured fat intake of clients by a food frequency list; the experimental group where labels were introduced could be compared to another experimental group where educational material, but no labels, were introduced, and a control group. No significant changes in fat intake could be detected. Both Sainsbury's (45) and Tesco (52) have provided some material showing that, after introduction of their signposting system (the Wheel of Health, a colour-coded GDA system, for Sainsbury's and a not colour-coded GDA system for Tesco), sales of some healthier products went up whereas sales of comparable products with less favourable nutrient information went down. The evidence is more anecdotal, though, since there is no control for other factors and details are not reported. Waitrose (58) commissioned a think-aloud study where informants were followed on a shopping trip, which yielded some interesting insights. For yoghurt, for example, the perception that this product generally is healthy led most informants not to look at additional nutrition information, and for both ready meals and sandwiches choices were determined by appearance, expected taste and convenience, 
and nutrition information played almost no role. For cereals, information is used when making decisions, but is no longer used once brand loyalty is established.

Overall, the studies give only very limited insight into label use. As with the results on self-reported perception, self-reported use is most likely heavily over-reported, though the demographic differences found are probably valid. The results on hypothetical use are interesting for formulating hypotheses on how signposting information, and especially colour codes, may be used, but need not have any relationship to actual use. The results on intention are interesting, but may be subject to demand effects. With regard to actual use, there are practically no studies.

We would also like to briefly draw attention to our distinction of different types of use. To the extent we have indicators about use at all, they mostly refer to use in the decision to buy the product that carries the label or not. As explained earlier, this is only the most direct and immediate form of use.

\section{Main conclusions}

Four major conclusions emerge across the studies. First, there is widespread interest for nutrition information on food packages. Consumers generally understand the link between food and health, and many have an interest in doing something about it, including the use of nutrition information. But the degree of interest differs between consumers and varies across situations and products; in addition, it coexists with other interests in food, notably interests in good taste, traditional eating and indulgence.

Second, consumers like the idea of simplified front of pack information. They may differ, though, in their liking for various formats, and these differences can be related to conflicting preferences for ease of use, being fully informed and not being coerced into certain types of behaviour. For example, many consumers like colour coding, but some regard reds and greens on food products as too pushy.

Third, most consumers understand the most common signposting formats in the sense that they believe that they understand them and that they can replay key information presented to them in an experimental situation.

Fourth, we have little insight into how labelling information is/will be used in a real-world shopping situation, and how it will affect consumers' dietary patterns.

It is worthwhile comparing the results of our review with the conclusions from the thorough review done by Cowburn and Stockley for the European Heart Network (European Heart Network 2003; Cowburn and Stockley 2005). Their conclusions on whether consumers look at nutrition labelling (roughly corresponding to what here is called perception) are largely identical to those in the present review. Also the conclusions about demographic differences are largely the same, as are the results on which nutrients people are most interested in (fat, calories, sugar). These conclusions are also supported by a review by Drichoutis et al. (2006). The European Heart Network review also concluded that actual label reading as revealed by protocol analysis was a good deal lower than reported label reading, which is in line with results in the Waitrose (58) study reviewed here.

Also the results on understanding are much in line. Conclusions pointed to the complexity of standard nutrition labelling and problems with technical terms, numerical calculations and, for some people, percentages.

A major difference is in the range of research on front of pack information covered in this review. While the EHN review covers studies on front of pack health logos, multinutrient front of pack information, such as multiple traffic lights and GDA-based systems, were not covered there, probably because they did not exist.

In discussing gaps in research, Cowburn and Stockley argued for a need to do more studies in European countries outside the UK. While UK studies still are very prominent in our review as well, we could identify more research being done in other countries, and even some comparative research across several countries. They also argued for a need to conduct studies with larger and more representative samples. This is still a problem for the academic papers identified, but the stakeholder-initiated research mostly works with samples of considerable size and good quality.

\section{Suggestions for future research}

One of our main conclusions was that there is widespread interest for nutrition information on food packages, but we also saw that this interest differs between people, situations and products. It would be very useful to have a European segmentation study on consumer interest in nutrition information - a study that distinguishes different types of consumers with regard to their interest in nutrition information, their interest in getting this information from labels, their perceived trade-offs between healthy eating and other food purchase motives, and the way in which their interest in nutrition information differs between products and situations. The study would quantify the size of the various segments found and profile them with regard to their current shopping behaviour, their current dietary patterns, their health status and their demographic characteristics. It would also take into account the interaction between consumer interest in nutritional information and actual availability of such information. It would be extremely helpful in discussing different ways of addressing different types of consumers when providing nutrition information, and also in putting nutrition 
information on package labels into the context of other information sources (Kremers et al. 2006).

We have, in this review, presented a hypothesis that could reconcile many of the diverse findings on which kinds of label formats consumers prefer, and this hypothesis should be tested in a study on determinants of consumer liking of different nutrition label formats. Our hypothesis was that liking is determined by three conflicting dimensions: the desire for simplicity, the desire for full information and the desire not to be coerced into particular types of food choices. Again, we suspect that consumers will differ in the weight they attach to these three dimensions, and in the way they trade them off against each other. The three dimensions should be measured and used in explaining liking for different types of formats. Also, the role of liking in inducing actual use of the information should be dealt with, drawing on relevant theory from social psychology.

We are in urgent need of studies on real-world label perception and low involvement learning. Almost all we know on label perception is based on consumer self-reports and are most likely grossly overestimated (Cowburn and Stockley 2005). In the real world, label perception, if it occurs at all, will be mostly in situations of time pressure and as part of decisions in which habitual behaviour and the use of heuristics play a big role. Label perception in the shop can be studied by observational methods and by at-the-shelf interviewing methods analogue to those that have been used in price perception research (e.g. Dickson and Sawyer 1990). Such studies can be complemented by eye-tracking experiments in the laboratory (Pieters and Warlop 1999) and by choice experiments that do not involve forced exposure to labels. They need to build on insights on low involvement learning, including subconscious perceptual processes (Grunert 1996). Such results on real-world label perception would allow the formulation of realistic expectations about label effects and more importantly could give important directions for improving label exposure and for label formats that encourage perception.

Another area that needs much more attention is the inferences that consumers make from the label information. The closest we come to this in the studies described is some insight into the degree to which consumers infer healthiness of a product from the label information. Quite obviously, consumers may draw different inferences from information about different nutrients, from different ways of presenting the information and from different patterns of information across the key nutrients, like different patterns of green, amber and red in colour-coded information. Theories on inference making, employing the accessibility-diagnosticity approach (Biehal and Chakravarti 1983; Kardes et al. 2004) could fruitfully be employed to shed light on this issue, which could be researched by a combination of qualitative studies employing the laddering methodology (Grunert and Grunert 1995) and experimental designs. Such studies would yield considerably more in-depth insight into how consumers' personal health theories affect the way in which they interpret nutrition labels and will in all likelihood reveal great variety in the way consumers interpret labels. This information, in turn, could be used for improving the design of labels and perhaps more importantly for calibrating the way in which labels are integrated into comprehensive systems for nutrition information.

Finally, we urgently need more insight into whether labels actually are used in guiding buying decisions and with what effect. This is a difficult topic and can only be investigated by using a combination of different approaches. An obvious way to start is to analyse scanner data from retailers. For product categories that are labelled or partly labelled, one could use a hedonic pricing approach, in which prices for products are explained by product attributes including the label information; if certain patterns of labelling information carry a positive hedonic price, this can be taken as evidence that consumers appreciate this information. The opposite analytic approach, namely using sales as the dependent variable, may be more straightforward, though. It would involve that sales of products are related to the label information, controlling for other important determinants of sales, most notably price, promotions and shelf space.

This kind of study would need to be complemented by research that looks more closely at the way consumers use labelling in their decision-making. Think-aloud studies are one promising approach here, though they do not capture the speed with which consumers process information in the supermarket. They should therefore be combined with choice experiments, where consumer choices, including the role of labelling information, are analysed by fitting choice algorithms, modelling different ways in which the labelling information is (or is not) used in decision-making.

And finally, one can attempt to relate use of label information to dietary intake, combining data on reported label use with food frequency diaries. This type of study has been done (e.g. Lin et al. 2004; Weaver and Finke 2003, both using US data), but it involves a causality problem, in that in a simple cross-sectional design it is not possible to find out whether label information affects dietary intake or whether people with certain dietary patterns read more labels. But panel designs and more advanced statistical methods could at least lead to some approximations to the direction of causality, a point also raised in the review by Drichoutis et al. (2006).

The list of references does not include the studies reviewed. Studies reviewed are listed in the Appendix.

Acknowledgements The authors would like to thank Gwen Bizet and Henriette Boel Nielsen for technical support in locating and analysing the studies cited.

Conflict of interest statement EUFIC receives funding from companies within the European food and drink industries sector, and Klaus G. Grunert received funding from EUFIC to carry out this review. 


\section{Appendix}

The appendix lists the sources on which the review is based, together with information on the sample and which main areas of our framework are dealt with and have been processed as part of the review. For abbreviations, see the end of the Appendix.

1. ACNielsen (2005) Global food labelling survey. PowerPoint presentation. ACNielsen. QT, 38 countries, $n=1,000$ in France, Germany, UK, $n=500$ in other countries K, P-S, P-E, U-P, S-SA

2. Armstrong G, Farley H, Gray J, Durkin M (2005) Marketing health-enhancing foods: implications from the dairy sector. Marketing Intelligence \& Planning 23:705-719. QT, Northern Ireland, $n=600$ I-E

3. ASDA Wal-Mart (2006) Front of pack signposting: a retail perspective. PowerPoint presentation. Gordon Maddan. QL, UK, 6 focus groups, QT, UK, $n=1,000, n=400$ I-E, L-CC, L-GDA, L-PS, U-P, S-SI

4. Bech-Larsen T, Grunert KG (2003) The perceived healthiness of functional foods: a conjoint study of Danish, Finnish and American consumers' perception of functional foods. Appetite 40:9-14. QT, DK, FIN, USA, $n=500$ per country S-IN

5. Bernues A, Olaizola A, Corcoran K (2003) Labelling information demanded by European consumers and relationships with purchasing motives, quality and safety of meat. Meat Science 65:1095-1106. QT, UK, F, I, $n=2,288$ I-G, I-E

6. Bureau Européen des Unions des Consommateurs (2005) Report on European consumers' perception of foodstuffs labelling. BEUC, Brussels. QT, 5 countries including D, DK, E, $n=600$ per country I-G, I-E, K, P-S, P-E, U-P, S-SA

7. British Market Research Bureau (2006) Results of BMRB omnibus survey on front of pack food labelling for the fast track group. BMRB. QT, UK, $n=1,000$ L-CO

8. Cadbury Schweppes (2005a) Consumer exploration and understanding of the traffic light food labelling initiative. Sundance, London. QL, UK, 3 focus groups U-P, L-G

9. Cadbury Schweppes (2005b) Consumer exploration and understanding of potential pack labelling initiatives. Sundance, London. QL, UK, 10 focus groups, 4 accompanied shopping trips I-G, K, U-P, L-G, L-GDA

10. Cereal Partners Worldwide (2006) GDA research UK, France, Germany-final report. PowerPoint presentation. Market Tools. QT, UK, F, D, $n=1,288$ L-CO, U-P, U-O, U-I, S-SI

11. Consommation Logement et Cadre de Vie/Ministère de l'Agriculture et de la Pêche (2004) Convention A02/22 relative à l'étude de la compréhension par les consommateurs de certaines mentions figurant dans l'étiquetage des denrées alimentaires préemballées et à leur perception de certaines allégations nutritionnelles, fonctionnelles et de santé. CLCV/DGAL, Paris. QT, F, $n=850$ I-G, S, K, P-S, U-P, U-O, S-SA

12. Consommation Logement et Cadre de Vie/Ministère de l'Agriculture et de la Pêche (2006) Étude relative aux besoins en matière d'étiquetage nutritionnel dans le cadre de la politique nutritionnelle. Convention CLCV/DGAL A05/08. CLCV/DGAL, Paris. QT, F, $n=$ 1,224 I-G, P-S, U-O, U-P, L-COS-SA, S-SI

13. Directorate General for Health and Consumer Protection (2005) The European consumers' attitudes regarding product labelling-qualitative study in 28 European countries. Optem, Versailles. QL, EU+ Norway and Switzerland, 4 focus groups per country I-G, I-E, U-P

14. Drichoutis A C, Lazaridis P, Nayga RM (2005a) Nutrition knowledge and consumer use of nutritional food labels. Eur Rev Agric Econ 32 (1):93-118. QT, GR, $n=330$ I-G, K, S-SA

15. European Food Information Council (2005) Nutrition information \& food labelling-results of the EUFIC consumer research conducted in May-June 2004. EUFIC Forum 2:1-6. QL, F, D, I, UK, 4 focus groups per country I-G, S, K, P-S, L-G, U-P

16. European Food Information Council (2006) An energy-based approach to nutrition information on food labels: results of the EUFIC consumer research 2005. EUFIC Forum 3. QL, F, D, NL, UK, 3 focus groups per country S-SA, U-P, L-CO, L-PS

17. Federatie Nederlandse Levensmiddelen Industrie (FNLI) (2005) Health and energy logo. PowerPoint presentation. Instituut voor Psychologisch Markt-en Motievenonderzoek QL, NL, 2 focus groups, 14 depth interviews L-G, L-CO, S-SI

18. Federatie Nederlandse Levensmiddelen Industrie (FNLI) (2006) Energielogo's en bewuste keuze logo's. PowerPoint presentation. Blauw Research, Rotterdam. QT, NL, $n=425$ L-CO, L-PS, U-I, S-IN

19. Food Safety Authority of Ireland (2003) Consumer attitudes to food safety in Ireland. Food Safety Authority of Ireland, Dublin. QT, IRL, $n=800$ I-G, I-E, P-S, P-E, U-P

20. Food Standards Agency (2002) Health claims on food packaging-consumer-related qualitative research. Forum Qualitative, London. QT, UK, 130 open interviews I-G, I-E, U-P, U-I, -S-SA

21. Food Standards Agency (2004a) Concept testing of alternative labelling of healthy/less healthy foods. Navigator, Gerrards Cross. QL, UK, 20 focus groups, 4 "friendship groups" I-E, K, P-S, U-P, L-G, L-CO, S-SA, S-SI

22. Food Standards Agency (2004b) Consumer attitudes to food standards wave 4. Food Standards Authority, London. QT, UK, n=3121 I-G, K, U-P, U-O, S-SA

23. Food Standards Agency (2005a) Qualitative signpost labelling refinement research. Synovate, London. QL, UK, 16 focus groups I-G, U-P, $\mathrm{U}-\mathrm{O}, \mathrm{L}-\mathrm{CO}, \mathrm{L}-\mathrm{CC}, \mathrm{S}-\mathrm{SI}$

24. Food Standards Agency (2005b) Quantitative evaluation of alternative food signposting concepts. Synovate, London. QT, UK, $n=2,676$ IG, L-CO, L-CC, S-SA, U-O 
25. Food Standards Agency (2005c) Signpost labelling-creative development of concepts. Navigator, Gerrards Cross. QL, UK, 6 focus groups U-P, L-CO, L-GDA, L-CC, S-SI

26. Gracia A, Loureiro M L, Nayga RM (in press) Do consumers perceive benefits from the implementation of a EU mandatory nutritional labelling program? Food Policy. QT, E, $n=400$ L-G, K, S-SA

27. Institute of Grocery Distribution (2004) Guideline daily amounts consumer research report. PowerPoint presentation. IGD, Watford. QL, UK, 9 focus groups, QT, UK, $n=1,000$ I-G, I-E, P-S, P-E, U-P, U-O, L-GDA, S-SI

28. Institute of Grocery Distribution (2005) Consumer attitudes to potential GDA formats. PowerPoint presentation. IGD, Watford. Institute of Grocery Distribution (2006) Best practice guidance on the presentation of guideline daily amounts. IGD, Watford. QL, UK, 6 focus groups, QT, UK, $n=1,028$ I-G, I-E, P-E, U-P, U-O, U-I, L-GDA, L-CC

29. Kellogg's (2004) Quantitative research to identify the best on-pack option for communicating GDA information. PowerPoint presentation. making more of research, Wallingford. QT, UK, $n=150$ P-T, L-GDA, U-P, U-O

30. Kellogg's (2005) Kellogg's Eye. PowerPoint presentation. The Oxford Research Agency. QT, UK, excerpts from ongoing data collection PS, P-E, L-G, U-O

31. KEPKA (2003) Summary of consumer research in 2003. No further details provided. QT, GR, details not reported. K, P-S, U-P, S-SA

32. Kraft Foods \& GfK NOP (2006) Understanding the health gap. Kraft Foods/GfK NOP, London. QT, UK, F, I, E, S, D, $n=500$ per country I-G, I-E, K, S-SA

33. Loureiro ML, Gracia A, Nayga RM (2006) Do consumers value nutritional labels? Eur Rev Agric Econ 33:249-268. QT, E, $n=400$ I-G, I-E

34. Mannell A, Brevard P, Nayga RM, Combris P, Lee R, Gloeckner J (2006) French consumers' use of nutrition labels. Nutr Food Sci 36:159168. QT, F, $n=355$ I-G, I-E, U-P, L-PS, S-SA

35. Masterfoods (2005) Nutritional labelling: qualitative exploration. PowerPoint presentation. Deep Blue Research, Ockham. QL, UK, 8 focus groups and 12 depth interviews I-E, K, U-P, L-G, L-CO, L-CC, L-GDA S-SA, S-SI

36. Masterfoods (2006) Nutritional labelling research-Be Treatwise initiative. PowerPoint presentation. Deep Blue Research, Ockham. QL, UK, 2 focus groups and 8 depth interviews I-G, K, P-S, L-G, U-P, S-SI

37. McDonald's (2005) McDonald's nutrition information initiative. PowerPoint presentation. 2CV Research, London. QL, UK, F, E, 14 focus groups in all I-E, K, P-S, L-CO, L-GDA

38. Nordic Council (2004) Nutrition labelling: Nordic recommendations based on consumer opinions. Nordic Council of Ministers, Copenhagen. QL, DK, S, N, FIN, 20 focus groups in all I-G, L-CO, L-GDA, U-P, S-SA

39. Nutrition \& Health Foundation (2005) NHF health \& lifestyle research 2005. Nutrition \& Health Foundation, Dublin. QL, IRL, 8 focus groups, QT, IRL, $n=1,000 \mathrm{I}-\mathrm{G}, \mathrm{U}-\mathrm{P}$

40. OCU (2004) Etiquetado nutricional-muy frecuente, pero poco informativo. OCU-Salud 56:14-17. QT, B, I, E, P, $n=1,500$ I-G, I-E, P-S, L-PS

41. Onderzoeks-en Informatiecentrum van de Forbruikerorganisaties (2005) Consumentenpercepties met betrekking tot de voedingswaardeetikettering. OIVO, Brussels. QL, B, 2 focus groups, QT, B, $n=486$ I-G, P-S, U-P

42. OMD Snapshots (2006) PowerPoint presentation. UK QT, UK, $n=700$ I-G, U-P

43. Saba A, Rosati S (2002) Understanding consumer perceptions of fermented yoghurt products using conjoint and generalised Procrustes analysis. Ital J Food Sci 14:339-350. QT, I, $n=120, n=15$ S-IN

44. Safefood (2004) Safetrak3-consumer tracking research October 2004. Safefood, Cork. QT, IRL+Northern Ireland, $n=828$ I-G, K, P-S, U-P

45. Sainsbury's (2006) Front of pack signpost labelling. PowerPoint presentation. Sainsbury's. QT, UK, $n=600$ P-S, U-P, S-SA, S-A

46. Schöffl H (2005) Wie gut lesbar und wie übersichtlich ist die Kennzeichnung von Lebensmitteln? Was lesen Konsumenten auf der Lebensmittelverpackung? Worüber wollen Konsumenten informiert werden? Arbeiterkammer Wien, Vienna. QT, A, $n=50$ I-G, P-S, U-P

47. Steenhuis I, van Assema P, van Breukelen G, Glanz K (2004) The effectiveness of nutrition education and labelling in Dutch supermarkets. Am J Health Promot 18:221-224. QT, NL, $n=2,203$ I-G, P-S, S-A

48. Stuart SA, Schröder MJA, Hughes A, Bower J (2004) Dimensional analysis of schoolchildren's food label comprehension: a pilot study. Int J Consum Stud 28:135-146. QT, UK, $n=19$ I-G, U-P, U-O

49. Svederberg E (2002) Consumers' views regarding health claims on two food packages. Department of Education, Lund University, Lund. QT, S, $n=449$ I-G, U-O, P-S, S-SA

50. Svederberg E, Asp N-G, Reuterswärd AL, Svensson L (2002) Läser och förstår konsumenter texter och symbolmärkning om näring och häls på livsmedelsförpackningar. Pedgogiska Institutionen, Lunds Universitet, Lund. QL, S, 30 respondents U-P, U-I

51. Tesco (2006a) Nutritional signpost research findings. PowerPoint presentation. Marketing Sciences Ltd., Winchester. QT, UK, $n=306$ P-S, P-E, L-CO, U-P, S-SI

52. Tesco (2006b) Informing the customer. PowerPoint presentation. Hutchins, I. QT, UK, sample not reported I-G, S-A

53. Unilever (2006) Front of pack nutrition labelling: testing effectiveness of different nutrition labelling formats front of pack in four European countries. Unilever Food \& Health Research Institute, Vlaardingen: Feunekes GIJ, Gortemaker IA, Willems A, Lion R. QT, study 1 UK, D, I, NL, $n=1,630$, study 2 UK, I, $n=776$ U-P, U-I, K, L-CO, S-IN,

54. Urala N, Lähteenmäki L (2003) Strength of health-related claims and their perceived advantage. Int J Food Sci Technol 38:815-826. QT, FIN, $n=958$ U-I

55. van Dillen SME, Hiddink GJ, Koelen MA, de Graaf C, van Woerkum CMJ (2003) Understanding nutrition communication between health professionals and consumers: development of a model for nutrition awareness based on qualitative consumer research. Am J Clin Nutr 77:1065S-1072S. QL, NL, 3 focus groups I-G, I-E

56. van Kleef E, van Trijp HCM, Luning P (2005) Functional foods: health claim-food product compatibility and the impact of health claim framing on consumer evaluation. Appetite 44:299-308. QT, NL, $n=124$ S-IN, L-G 
57. Which? (2006) Food labeling study. Conquest Research. QT, UK, $n=636$ I-G, U-P, U-O

58. Waitrose (2005) Traffic light labelling. PowerPoint presentation. Taylor Nelson Sofres. QL, UK, 8 focus groups, 10 accompanied shopping trips I-G, I-E, P-S, L-CO, U-P, S-SA, S-SI

Abbreviations:

$Q T$ quantitative, $Q L$ qualitative, $I-G$ interest-general, $I-E$ interest-effect of types of consumers, types of products, type of situations, type of info, $K$ knowledge, $S$ search, $P-S$ perception-self-reported reading and awareness, $P-E$ effects of types of consumers, type of situation, type of info on self-reported reading and awareness, $P-F$ perception-field study, $P-T$ perception, tachistoscopic study, $L-G$ liking-general, $L-C O$ liking, comparison of different FoP formats, $L-C C$ liking, colour coding, $L-G D A$ liking, different GDA formats, $L-P S$ liking, per serving/per $100 \mathrm{~g}, U-P$ understanding, perceived, $U-I$ understanding, inferences about healthiness, $U-O$ understanding, objective tests, $S$ - $S A$ use, self-reported actual, $S$-SI use, self-reported imagined, $S$-IN use, effect on intentions, $S$ - $A$ use, actual

\section{References}

Baltas G (2001) Nutrition labeling: issues and policies. Eur J Marketing 35:708-721

Bettman JR (1979) An information processing theory of consumer choice. Addison-Wesley, Reading, MA

Bettman J, Luce MF, Payne JW (1998) Constructive consumer choice processes. J Consumer Res 25:187-217

Biehal G, Chakravarti D (1983) Information accessibility as a moderator of consumer choice. J Consumer Res 10:1-14, June

Bryman A, Bell E (2003) Business research methods. Oxford University Press, Oxford

Cowburn G, Stockley L (2005) Consumer understanding and use of nutrition labeling: a systematic review. Public Health Nutr 8:21-28

Dickson PR, Sawyer AG (1990) The price knowledge and search of supermarket shoppers. J Marketing 54(3):42-53

Drichoutis AC, Lazaridis P, Nayga RM (2006) Consumers' use of nutritional labels: a review of research studies and issues. Acad Marketing Sci Rev, no. 9. Available http://www.amsreview.org/ articles/drichoutis09-2006.pdf

Eagly AH, Chaiken S (1993) The psychology of attitudes. Harcourt Brace College Publishers, Fort Worth, TX

Engel JF, Kollat DT, Blackwell RD (1968) Consumer behavior. Holt, Rinehart \& Winston, New York

European Heart Network (2003) A systematic review of the research on consumer understanding of nutrition labeling. European Heart Network, Brussels

Grunert KG (1996) Automatic and strategic processes in advertising effects. J Marketing 60(4):88-101
Grunert KG, Grunert SC (1995) Measuring subjective meaning structures by the laddering method: theoretical considerations and methodological problems. Int J Res Marketing 12:209-225

Kardes FR, Posavac SS, Cronley ML (2004) Consumer inference: a review of processes, bases, and judgment contexts. J Consumer Psychol 14(3):230-256

Kremers SPJ, de Bruijn GJ, Visscher TLS, van Mechelen W, de Vries NK, Brug J (2006) Environmental influences on energy balance-related behaviors: a dual-process view. Int J Behav Nutr Phys Activity 3:9

Lavidge RJ, Steiner GA (1961) A model for predictive measurements of advertising effectiveness. J Marketing 25(4):59-62

Lin CTJ, Lee JY, Yen ST (2004) Do dietary intakes affect search for nutrient information on food labels? Soc Sci Med 59:1955-1967

McGuire WJ (1985) Attitudes and attitude change. In: Lindzey G, Aronson E (eds) The handbook of social psychology, Vol. 2, 3rd edn. Random House, New York, pp 233-346

Peter JP, Olson JC, Grunert KG (1999) Consumer behaviour and marketing strategy. McGraw-Hill, Maidenhead

Petty RE, Cacioppo JT (1981) Attitudes and persuasion: classic and contemporary approaches. Brown, Dubuque, IO

Petty RE, Cacioppo JT (1986) Communication and persuasion: central and peripheral routes to attitude change. Springer, New York

Pieters R, Warlop L (1999) Visual attention during brand choice: the impact of time pressure and task motivation. Int J Res Marketing 16:1-16

Solomon M, Bamossy G, Askegaard S, Hogg MK (2006) Consumer behaviour, a European perspective, 3rd edn. Prentice Hall, Harlow

Weaver D, Finke M (2003) The relationship between the use of sugar content information on nutrition labels and the consumption of added sugars. Food Policy 28:213-219 